\title{
Inbreeding depression in benign and stressful environments
}

\author{
P Armbruster ${ }^{1}$ and DH Reed ${ }^{2}$ \\ ${ }^{1}$ Department of Biology, Reiss Science Bldg. 406, Georgetown University, 37th E O Streets NW, Washington, DC 20057-1229, USA; \\ ${ }^{2}$ Department of Biology, The University of Mississippi, PO Box 1848, MS 38677-1848, USA
}

\begin{abstract}
Understanding the consequences of inbreeding has important implications for a wide variety of topics in population biology. Although it is often stated in the literature that the deleterious effects of inbreeding (inbreeding depression) are expected to be more pronounced under stressful than benign conditions, this issue remains unresolved and controversial. We review the current literature on the relationship between the magnitude of inbreeding depression and environmental stress and calculate haploid lethal equivalents expressed under relatively benign and stressful conditions based on data from 34 studies. Inbreeding depression increases under stress in $76 \%$ of cases, although this increase is only significant in $48 \%$ of the studies considered. Estimates of
\end{abstract}

lethal equivalents are significantly greater under stressful (mean $=1.45$, median $=1.02)$ than relatively benign $($ mean $=$ 0.85 , median $=0.61$ ) conditions. This amounts to an approximately $69 \%$ increase in inbreeding depression in a stressful vs a benign environment. However, we find strong lineage effects to be ubiquitous among studies that examine inbreeding depression in multiple environments, and a prevalence of conditionally expressed deleterious effects within lineages that are uncorrelated across environments. These results have important implications for both evolutionary and conservation biology.

Heredity (2005) 95, 235-242. doi:10.1038/sj.hdy.6800721; published online 3 August 2005

Keywords: inbreeding depression; genotype-environment interactions; stress; fitness; conservation genetics

\section{Introduction}

Inbreeding depression refers to the reduction in the fitness of offspring produced by consanguineous mating, and the deleterious effects of inbreeding have been known for more than a century (Darwin, 1876). Understanding the causes and consequences of inbreeding depression is fundamental to a wide variety of topics in population biology, including the evolution of mating systems (Charlesworth and Charlesworth, 1987; Uyenoyama et al, 1993), dispersal strategies and social behavior (Thornhill, 1993), artificial breeding of agricultural stocks (Falconer and Mackay, 1996), and the maintenance of rare and endangered species (Hedrick and Kalinowski, 2000; Reed and Frankham, 2003).

Population biologists are also concerned with understanding how environmental variation might interact with inbreeding depression to affect the fitness of individuals (ie, is inbreeding depression more severe under environmental stress?, Figure 1). This interest is related to several issues. For example, how might inbreeding depression measured under artificial laboratory, greenhouse, or zoo conditions relate to the effects of inbreeding depression in presumably more stressful natural environments? Furthermore, how might spatial and/or temporal variation in environmental conditions interact with the effects of inbreeding depression over

Correspondence: P Armbruster, Department of Biology, Reiss Science Bldg. 406, Georgetown University, 37th \& O Streets NW, Washington, DC 20057-1229, USA. E-mail: paa9@georgetown.edu

Received 8 January 2005; accepted 27 June 2005; published online 3 August 2005 ecological or evolutionary time scales, and how might such interactions affect evolutionary dynamics and extinction processes?

It is frequently claimed that inbreeding depression is greater in more stressful environments (Roff, 1997; Frankham et al, 2002). However, over a wide range of taxonomic and biological groupings, studies that find statistically increased inbreeding depression under environmental stress are slightly less numerous than those that do not (see Results below). Thus, despite its immediate concern to evolutionary and conservation biologists, this subject remains controversial (Keller and Waller, 2002).

Herein, we review 34 studies, 14 of which have been published in the last 3 years, examining the interaction between inbreeding depression and environmental stress. We then calculate the haploid lethal equivalents expressed under relatively benign and stressful conditions in order to quantify the interaction between inbreeding depression and environmental stress. Although recent reviews on inbreeding depression in the wild (Keller and Waller, 2002), and inbreeding depression and conservation (Hedrick and Kalinowski, 2000) have touched on this issue, neither has explicitly focused on the environmental dependency of inbreeding depression nor presented a comprehensive evaluation of all the currently available literature on this topic.

\section{Definitions}

\section{Stress}

Nearly all studies either implicitly or explicitly recognize a 'stressful' environment as one that reduces fitness 


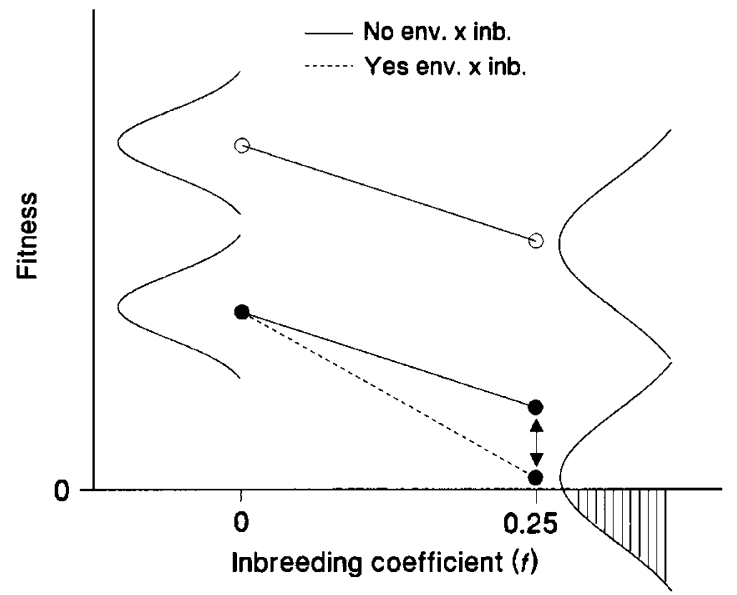

Figure 1 Hypothetical fitness distributions and mean fitness for control $(f=0)$ and inbred $(f=0.25)$ treatments in benign $(O)$ and stressful $(\bullet)$ environments. Negative slopes connecting the mean fitness estimates in each environment indicate inbreeding depression. The solid lines indicate no environment-by-inbreeding interaction (No env. $\times$ inb.), the dashed line indicates an environment-by-inbreeding interaction is present (Yes env. $\times$ inb.). The double arrow ( $\uparrow$ ) illustrates the effect of the truncated portion of the fitness distribution for the inbred treatment in a stressful environment (indicated by cross-hatching $(|| \mid)$ ).

(or fitness components) relative to more benign conditions (Hoffmann and Parsons, 1991). However, it should be noted that this definition is not always applied correctly when citing other studies. For example, both Chen (1993) and Pray et al (1994) are sometimes cited as supporting the conclusion that inbreeding depression is more pronounced under stressful conditions. Chen (1993) reared outbred and inbred (one generation of full-sib mating) European land snails (Arianta arbustorum) in the laboratory and a garden, finding evidence for inbreeding depression for survivorship over 100 days in the garden environment but not the laboratory. However, survivorship of the snails was higher in the garden than in the laboratory. Pray et al (1994) found that inbreeding depression of both male and female Tribolium castaneum was more pronounced in a variable than a constant humidity environment. However, as noted by Pray et al (1994), both sexes actually had higher fitness in the variable rather than constant humidity environment, although the difference was only significant for males. According to the definition discussed above, inbreeding depression in these studies was actually more pronounced in the benign rather than stressful environment. These results, therefore, emphasize that laboratory and/or constant environments can actually be more stressful than more natural and/or variable environments. In our analysis, we define the stressful environment as one that reduces fitness relative to another environment.

\section{Fitness}

The most meaningful measurement of fitness in a constantly expanding population with overlapping generations is the Malthusian parameter, $r$ (Charlesworth, 1980). However, unambiguously identifying a single parameter acting to maximize fitness in a natural population will often be difficult or impossible. Nevertheless, it seems reasonable to assume that composite indices of fitness, which integrate measures of performance over as many components of lifetime reproductive success as possible are most meaningful.

In some cases, authors will cite a study as supporting the hypothesis that stressful conditions increase inbreeding depression when an inbreeding-by-environment interaction is detected for one fitness component, but not overall performance. However, such conclusions may be misleading, because inbreeding depression affecting one component of the lifecycle may lead to reduced competition and/or enhanced growth and/or fertility in other portions of the lifecycle. For example, in a study of inbreeding in a natural population of the Great Tit (Parus major) in Holland, Van Noordwijk and Scharloo (1981) found evidence of substantial inbreeding depression for egg hatching success. However, inbred clutches had nonsignificantly higher fledgling recruitment relative to noninbred clutches, which may have been caused by reduced competition in clutches with low hatching rates. Such trade-offs between fitness components may be common (eg, Sinervo, 1990; Sinervo et al, 1992; Carriere and Roff, 1995; Preziosi et al, 1996; Reed and Bryant, 2000). These considerations underscore previous arguments that have been made (Charlesworth and Charlesworth, 1987) regarding the importance of measuring composite indices of fitness, rather than fitness correlates or components, when evaluating the consequences of inbreeding.

\section{The literature}

A literature survey was performed using key words and citation searches of the work available on inbreeding depression in plants and animals. In order to avoid publication bias, we have included studies that report nonsignificant effects of inbreeding under benign or stressful conditions. We have restricted our coverage to studies that perform direct experimental manipulation to measure inbreeding depression in more than one environment. We have omitted studies that rely on indirect comparisons of different populations of the same species (eg, Crnokrak and Roff, 1999) due to the large number of potentially confounding factors which may obscure the results of such comparisons and the emerging pattern that inbred populations and lineages from a single species often respond differently to inbreeding and/or environmental stress (eg Kärkkäinen et al, 1996; Cheptou et al, 2000a; Carr and Eubanks, 2002; Carr et al, 2003). We also have not included studies that rely on molecular marker data to infer relative levels of inbreeding, since these data often explain a low proportion of the variation in actual inbreeding (Hedrick et al, 2001). We have also excluded the substantial literature on heterosis by environment interactions. Despite common statements to such effect in the literature, inbreeding depression is not simply the reverse manifestation of heterosis (Lynch and Walsh, 1998; Whitlock et al, 2000).

A summary of the papers, we considered is outlined in Appendix A1. They include studies on 11 plant, nine invertebrate, and one vertebrate species. The stress factors include exposure to insecticides and other noxious or toxic chemicals, nutrient deprivation, temperature and desiccation stress, the effects of competition 
and parasitism, and comparisons between laboratory and field environments.

For each study, we computed $B$, the number of haploid lethal equivalents (Morton et al, 1956) under benign and stressful conditions as:

$$
B=-\frac{1}{f} \ln \left(\frac{w_{f}}{w_{0}}\right)
$$

where $f$ is the inbreeding coefficient, and $w_{f}$ and $w_{o}$ are the mean fitness of inbred and outbred (control) individuals, respectively (Hedrick, 2000). The number of haploid lethal equivalents, $B$, describes the rate at which the logarithm of fitness (or fitness components) declines with inbreeding, and is equal to 0 when there is no inbreeding depression. Calculating lethal equivalents is a common method for comparing the effects of inbreeding among studies, taxa and/or environmental conditions (Ralls et al, 1988; Keller et al, 2002) because it provides a measure which standardizes the effects of different levels of inbreeding $(f)$.

In many instances, the data sets that we used in this study measured more than one fitness component. In these cases, we used the single fitness component expected to most closely correlate with total fitness in our analysis (ie, composite measures such as lifetime reproductive success were favored over fecundity or survival, and fecundity or survival were given preference over growth rates or biomass). Several studies measured inbreeding depression under benign and stressful conditions in more than one species (see Appendix A1). Furthermore, several of the studies measured the effects of inbreeding under one benign environment and multiple stressful environments. In these cases, we included estimates of lethal equivalents expressed under multiple, independent stressful environments in our analysis, and thus the number of estimates of $B$ from stressful environments $(n=52)$ exceeds the number of estimates of $B$ from benign environments $(n=39$, see Appendix A1).

In order to evaluate the consequences of inbreeding under benign and stressful conditions we performed a paired $t$-test to evaluate the null hypothesis that the expression of haploid lethal equivalents $(B)$ was equal under benign and stressful conditions. Estimates of $B$ expressed under relatively benign and stressful conditions were subjected to the transformation $\ln (x+1)$ and the degrees of freedom were determined based on the number of independent estimates of $B_{\text {benign }}(n=39)$. In order to examine factors that might influence the change in levels of inbreeding depression under benign $v s$ stressful conditions, we calculated the proportional change in inbreeding depression as $B_{\text {stress }} / B_{\text {benign }}$. The distribution of $B_{\text {stress }} / B_{\text {benign }}$ was highly skewed, but a natural $\log$ transformation of $\left(B_{\text {stress }}+1\right) /\left(B_{\text {benign }}+1\right)$ produced an approximately normal distribution. We performed analysis of variance (ANOVA) on $\ln \left[\left(B_{\text {stress }}+1\right) /\left(B_{\text {benign }}+1\right)\right]$ with fitness measurement (composite vs noncomposite, $\mathrm{df}=1$ ), stress type (see Appendix $\mathrm{A} 1, \mathrm{df}=4$ ), and taxa (plant $v$ animal, $\mathrm{df}=1$ ) as fixed effects. Similar to the paired $t$-test described above, residual degrees of freedom were determined based on 39 independent estimates of $B_{\text {benign. All }}$ statistical analyses were performed in S-Plus 6.2 (Insightful, 2001).

\section{Results}

Inbreeding depression increased under relatively stressful conditions in $76 \%$ of the cases we examined, although this increase was only statistically significant in $48 \%$ of cases. The mean haploid lethal equivalents expressed under benign conditions was $0.85(\mathrm{SE}=0.14, n=39)$, while under stressful conditions the mean $B$ was 1.45 $(\mathrm{SE}=0.17, n=52)$. Because the distribution of $B$ under both benign $\left(B_{\text {benign }}\right)$ and stressful $\left(B_{\text {stress }}\right)$ conditions was markedly non-normal (Figure 2), the median value should be considered a better estimate of central tendency. Median $B_{\text {benign }}$ was 0.61 , and median $B_{\text {stress }}$ was 1.02. This difference was highly significant by paired $t$-test $(t=4.49, \mathrm{df}=38, P<0.001)$. Using either the mean or the median produced a number of haploid lethal equivalents that was approximately 69\% greater, on average, in a stressful environment than in a benign environment $($ mean $=70 \%$, median $=68 \%)$.

ANOVA indicated that $\ln \left[\left(B_{\text {stress }}+1\right) /\left(B_{\text {benign }}+1\right)\right]$ was not significantly affected by the fitness measurement (composite vs noncomposite, see Appendix A1) employed in a study $\left(\mathrm{F}_{1,27}=0.47, P=0.50\right)$, stress type $\left(\mathrm{F}_{4,27}=0.32, P=0.58\right)$, taxa $\left(\mathrm{F}_{1,27}=0.87, P=0.36\right)$, stressby-taxa $\left(\mathrm{F}_{2,27}=0.71, P=0.50\right)$ nor stress-by-fitness interaction $\left(\mathrm{F}_{3,27}=1.56, P=0.22\right)$. The conclusions of the same analysis with nontransformed data were qualitatively equivalent.
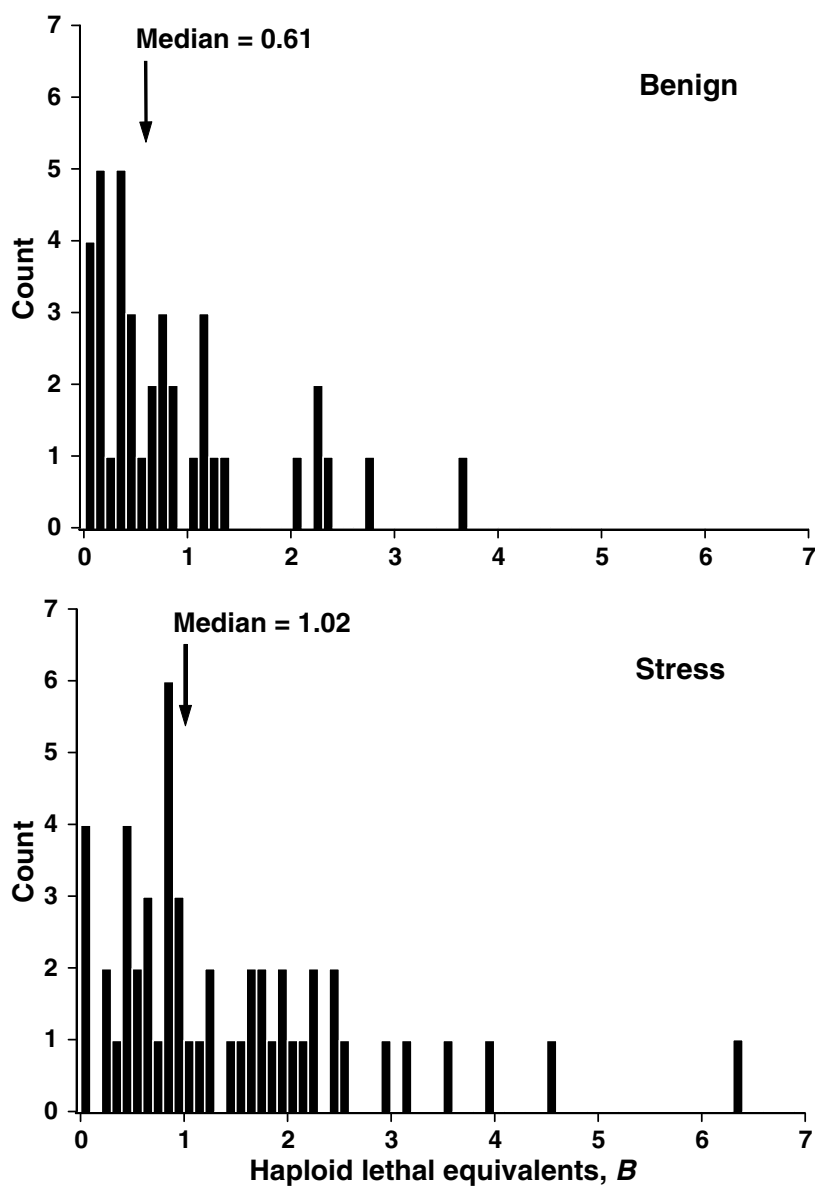

Figure 2 Haploid lethal equivalents $(B)$ under relatively benign $(n=39)$ and stressful $(n=52)$ conditions from 34 studies described in Appendix A1. 
The 'file drawer' problem (ie unpublished data) is a concern with any meta-analysis (Osenberg et al, 1999). In this study, the distribution of effect sizes displays the funnel shape indicative of a lack of publication bias (Palmer, 2000) and the number of studies reporting nonsignificant results outnumbers those reporting significant results. Thus, publication bias seems extremely unlikely.

\section{Discussion}

\section{Is inbreeding depression greater in more stressful environments?}

We find that, on average, inbreeding depression is greater in relatively stressful environments (Figure 2). The median number of lethal equivalents expressed under environmental stress was $69 \%$ greater than under relatively benign environmental conditions. Factors contributing to the lack of clarity on this subject prior to this study are: (1) The large amount of variation in expression of lethal equivalents from different studies (Figure 2) and sometimes among different measures in a single study (see below). (2) The low statistical power associated with the small sample sizes and/or a limited number of inbred lineages used in single experiments. Suggestions have been made elsewhere that a minimum of between 20 (Keller and Waller, 2002) and 100 (Lynch, 1988) inbred lineages should be examined in studies of inbreeding depression, but $64 \%$ of the studies we examined employed less than 20 inbred lineages. (3) Studies are often cited in an inconsistent manner. Definitions of 'stress' are often not considered carefully, the distinction between fitness components and overall fitness is neglected, or studies are cited as reporting increased inbreeding under stress when only one or a few of many traits display such a pattern.

\section{Variation in response to inbreeding under stress}

It is important to note the large number of instances in which inbreeding did not increase under stress. In $24 \%$ of the data sets, inbreeding depression actually decreased in the stressful environment. ANOVA examining fitness measurement, stress type, and taxa did not identify any of these factors as significantly affecting the increase of inbreeding depression under stress, although we note that this particular analysis has somewhat limited statistical power. Furthermore, part of this unexplained variation is likely due to the idiosyncrasies of the study organism or population, variation among the environmental conditions used, experimental procedures, and specific lineage effects (see below). This large amount of unexplained variance emphasizes a recurrent theme (see below), that accurate predictions regarding the response of specific populations or lineages to inbreeding under stress will often be difficult or impossible.

\section{Lineage effects}

Genetic variance among lineages is expected to increase under inbreeding (Falconer and Mackay, 1996; Lynch and Walsh, 1998). Of the 22 studies where lineage effects could be tested for, $17(77 \%)$ found significant amonglineage variation. Most commonly, investigators testing the effects of inbreeding under multiple environmental conditions generate replicate inbred lineages by full-sib mating while maintaining a control (ie, noninbred) population. After one or more generations of full-sib mating the performance of inbred and control offspring is measured under two or more sets of environmental conditions. Under a purely additive model of gene action the total genetic variation across all replicate lineages is expected to increase according to $(1+f) \mathrm{Vg}$ where $f$ is the inbreeding coefficient, and $\mathrm{Vg}$ is the genetic variance in the control (noninbred) population (Falconer and Mackay, 1996). If nonadditive genetic effects (dominance and epistasis) contribute to gene expression, inbreeding can actually increase (rather than decrease) within-lineage variance (Goodnight, 1987), and the increase in among-lineage variance with inbreeding can be substantially larger than the additive expectation (Goodnight, 1988).

One potential implication of an increase in total population genetic variation with inbreeding for detecting inbreeding by environment interactions is illustrated in Figure 1. Figure 1 illustrates a hypothetical situation in which an inbred population in a stressful environment contains a large number of individuals who cannot survive and/or reproduce (ie, fitness of zero). The combination of increased variance in the inbred population and the fact that individuals cannot have fitness less than zero means that as environmental conditions become increasingly severe, the expression of inbreeding depression is diminished. This is because the increased variance in fitness in the inbred population allows natural selection to act against the least fit genotypes, reducing the cumulative loss of fitness predicted to occur in the benign environment. In many studies that have failed to detect inbreeding by stress interactions the fitness (components) of inbred treatments in the stressful environments do indeed approach zero, as illustrated in Figure 1 (Dahlgaard et al, 1995; Norman et al, 1995; Hauser and Loeschcke, 1996; Armbruster et al, 2000).

One very clear pattern to emerge from the studies we reviewed is that different populations of a single species, and different inbred lineages from the same population, often exhibit highly variable responses to inbreeding under stressful conditions (Pray et al, 1994; Bijlsma et al, 1999; Dahlgaard and Hoffmann, 2000; Fowler and Whitlock, 2002; Reed et al, 2002; Carr et al, 2003; Haag et al, 2003). The implication of this result is that different alleles and/or loci are determining susceptibility to stresses in different inbred lineages and/or populations. These results emphasize the difficulty in predicting how managed populations may respond to inbreeding, particularly under environmentally variable conditions (Hedrick and Kalinowski, 2000). Inbred lineages that have relatively high fitness under benign farm, laboratory, or zoo conditions may fare relatively poorly in a natural environment, and therefore are will not necessarily be the most suitable for reintroduction programs (Pray et al, 1994; Bijlsma et al, 2000; Reed and Bryant, 2000). Furthermore, attempts to 'purge' inbreeding depression by deliberately inbreeding managed populations under relatively benign conditions (eg, Templeton and Read, 1983) are unlikely to be successful since alleles causing susceptibility to environmental stress will be unlikely to be effectively removed from such populations (Bijlsma et al, 2000; Reed and Bryant, 2001). 
Do the same loci contribute to stress resistance in different environments?

Even if different alleles are fixed or drift to high frequency in different inbred lineages as described above, it is possible that individual alleles might have general stress-resistance effects across different types of stresses. Such an effect would cause individual inbred lineages to have highly correlated norms of reaction across different stressful environments.

Although the number of available studies addressing this question is small, preliminary results suggest that the expression of deleterious recessive alleles underlying inbreeding depression may often depend on specific environmental conditions (Heywood, 1993; Bijlsma et al, 1999; Dahlgaard and Hoffmann, 2000; Reed and Bryant, 2001; Haag et al, 2003; Reed et al, 2003).

Recent studies by Vermeulen and Bijlsma (2004a, b) have demonstrated lineage- and temperature-specific adult mortality in inbred Drosophila melanogaster lines caused by the expression of temperature-sensitive lethals and semi-lethals. These studies thus provide an example of a specific mechanism underlying lineage- and environment-specific inbreeding depression, although the precise genetic basis (ie one vs multiple loci, chromosomal location(s)) has not yet been determined (Vermeulen and Bijlsma, 2004b).

The implications of these results is that different alleles and/or loci determine resistance to different stresses, and thus it will be difficult or impossible to select for general 'stress-resistant' lineages which perform well under multiple environmental challenges. The large degree of variation in how species and populations respond to different sorts of stress means that a priori predictions will almost always be unreliable.

In their review of inbreeding depression in wild populations, Keller and Waller (2002) wrote that 'Although it is often asserted in the literature that inbreeding depression in greater under stress or field conditions, this pattern is neither universally supported nor theoretically resolved'. Results of our analysis indicate that averaging across a wide range of taxa, inbred lineages, and environmental stress conditions, the effects of inbreeding depression do tend to increase under environmental stress. However, lineage- and stress-specific responses to inbreeding are widespread.

To develop a more unified framework regarding the effects of inbreeding under stress, we suggest first that studies identifying the specific loci contributing to inbreeding depression, and characterizing their environmental sensitivity will be important (eg Vermeulen and Bijlsma, 2004a, b). Also important will be studies of inbreeding under natural conditions (ie see Appendix A1). Many of the studies we examined used artificial stress factors such as chemicals or heavy metals (Bijlsma et al, 1999, 2000; Dahlgaard and Hoffmann, 2000; Reed et al, 2002; Kristensen et al, 2003). Resistance to these types of stress will often be determined by alleles at a single or few genetic loci (Hoffmann and Parsons, 1991), and may provide a poor reflection of the consequences of inbreeding under more natural conditions when a wide variety of physiological and/or behavioral challenges confront organisms, and potentially a much wider suite of genetic loci are involved in resistance. Another important area of future research is to develop a theoretical framework for investigating inbreeding depression by environmental interactions. Few models establishing such a framework currently exist (but see Cheptou and Schoen, 2002). Models incorporating both genetics and demography (eg Mills and Smouse, 1994), and explicitly modeling interactions between inbreeding depression and environmental variation should play an important role in guiding experimental work.

\section{Acknowledgements}

We thank L Stevens, C Goodnight, R Frankham and two anonymous referees for helpful comments on previous versions of this manuscript.

\section{References}

Armbruster P, Hutchinson RA, Linvell T (2000). Equivalent inbreeding depression under laboratory and field conditions in a tree-hole-breeding mosquito. Proc Roy Soc Lond B 267: 1939-1946.

Bijlsma R, Bundgaard J, Boerema AC (2000). Does inbreeding affect the extinction risk of small populations?: predictions from Drosophila. J Evol Biol 13: 502-514.

Bijlsma R, Bundgaard J, Van Putten WF (1999). Environmental dependence of inbreeding depression and purging in Drosophila melanogaster. J Evol Biol 12: 1125-1137.

Carr DE, Eubanks MD (2002). Inbreeding alters resistance to insect herbivory and host plant quality in Mimulus guttatus (Scrophulariaceae). Evolution 56: 22-30.

Carr DE, Murphy JH, Eubanks MD (2003). The susceptibility and response of inbred and outbred Mimulus guttatus to infection by Cucumber mosaic virus. Evol Ecol 17: 85-103.

Carriere Y, Roff DA (1995). The evolution of offspring size and number: a test of the Smith-Fretwell model in three species of crickets. Oecologia 102: 389-396.

Charlesworth B (1980). Evolution in Age-Structured Populations. Cambridge University Press: Cambridge, UK.

Charlesworth B, Charlesworth D (1987). Inbreeding depression and its evolutionary consequences. Ann Rev Ecol Syst 18 237-268.

Chen X (1993). Comparison of inbreeding and outbreeding in hermaphroditic Arianta arbustorum (L. land snail). Heredity 71: 456-461.

Cheptou P-O, Berger A, Blanchard A, Collin C, Escarré J (2000a). The effect of drought stress on inbreeding depression in four populations of the Mediterranean outcrossing plant Crepis sancta (Asteraceae). Heredity 85: 294-302.

Cheptou P-O, E. Imbert J, Lepart J, Escarré J (2000b). Effects of competition on lifetime estimates of inbreeding depression in the outcrossing plant Crepis sancta (Asteraceae). J Evol Biol 13: 522-531.

Cheptou P-O, Lepart J, Escarré J (2001). Inbreeding depression under intraspecific competition in a highly outcrossing population of Crepis sancta (Asteraceae): evidence for frequency-dependant variation. Am J Bot 88: 1424-1429.

Cheptou P-O, Schoen DJ (2002). The cost of fluctuating inbreeding depression. Evolution 56: 1059-1062.

Crnokrak P, Roff DA (1999). Inbreeding depression in the wild. Heredity 83: 260-270.

Dahlgaard J, Hoffmann AA (2000). Stress resistance and environmental dependency of inbreeding depression in Drosophila melanogaster. Conserv Biol 14: 1187-1192.

Dahlgaard J, Krebs RA, Loeschcke V (1995). Heat-shock tolerance and inbreeding in Drosophila buzzatii. Heredity 74: 157-163.

Dahlgaard J, Loeschcke V (1997). Effects of inbreeding in three life stages of Drosophila buzzati after embryos 
were exposed to a high temperature stress. Heredity 78: $410-416$.

Darwin C (1876). The Effects of Cross and Self Fertilisation in the Vegetable Kingdom. John Murray: London, UK.

Dudash M (1990). Relative fitness of selfed and outcrossed progeny in a self-compatible, protandrous species, Sabatia angularis L. Gentianaceae): a comparison in three environments. Evolution 44: 1129-1139.

Eckert CG, Barrett SCH (1994). Inbreeding depression in partially self-fertilizing Decodon verticillatus (Lythraceae): population-genetic and experimental analyses. Evolution 48: 952-964.

Falconer DS, Mackay TFC (1996). Introduction to Quantitative Genetics, 4th edn, Longman, Harlow: UK.

Fowler K, Whitlock MC (2002). Environmental stress, inbreeding, and the nature of phenotpyic and genetic variance in Drosophila melanogaster. Proc Roy Soc Lond B 269: 677-683.

Frankham R, Ballou JD, Briscoe DA (2002). Introduction to Conservation Genetics. Cambridge University Press: Cambridge, UK.

Goodnight C (1987). On the effect of founder events on epistatic genetic variance. Evolution 41: 80-91.

Goodnight C (1988). Epistasis and the effect of founder events on the additive genetic variance. Evolution 42: 441-454.

Haag CR, Hottinger JW, Riek M, Ebert D (2002). Strong inbreeding depression in a Daphnia metapopulation. Evolution 56: 518-526.

Haag CR, Sakwiñska O, Ebert D (2003). Test of synergistic interaction between infection and inbreeding in Daphnia magna. Evolution 57: 777-783.

Hauser TPL, Loeschcke V (1996). Drought stress and inbreeding depression in Lychnis flos-cuculi (Caryophyllaceae). Evolution 50: $1119-1126$.

Hedrick PW (2000). Genetics of Populations. Jones and Bartlett Publishers: Massachusetts.

Hedrick PW, Kalinowski ST (2000). Inbreeding depression in conservation biology. Ann Rev Ecol Syst 31: 139-162.

Hedrick P, Fredrickson R, Ellegren H (2001). Evaluation of $\mathrm{d}(\mathrm{bar})^{2}$ a microsatellite measure of inbreeding and outbreeding, in wolves with a known pedigree. Evolution 55: 1256-1260.

Henry P-Y, Pradel R, Jarne P (2003). Environment-dependant inbreeding depression in a hermaphroditic freshwater snail. J Evol Biol 16: 1211-1222.

Heywood JS (1993). Biparental inbreeding depression in the self-incompatable annual plant Gaillardia pulchella. Am J Bot 80: $545-550$.

Hoffmann AA, Parsons PA (1991). Evolutionary Genetics and Environmental Stress. Oxford University Press: New York.

Insightful (2001). S-Plus 6 for Windows User's Guide. Insightful Corporation: Washington.

Ivey CT, Carr DE, Eubanks MD (2004). Effects of inbreeding in Mimulus guttatus on tolerance to herbivory in natural environments. Ecology 85: 567-574.

Jiménez JA, Hughes KA, Alaks G, Graham L, Lacy RC (1994). An experimental study of inbreeding depression in a natural habitat. Science 266: 271-273.

Johnston MO (1992). Effects of cross and self-fertilization on progeny fitness in Lobelia cardinalis and L. siphilitica. Evolution 46: 688-702.

Joron M, Brakefield P (2003). Captivity masks inbreeding effects on male mating success in butterflies. Nature 424: 191-194.

Kärkkäinen K, Koski V, Savolainen O (1996). Geographic variation in the inbreeding depression of Scots pine. Evolution 50: 111-119.

Keller LF, Grant PR, Grant RB, Petren K (2002). Environmental conditions affect the magnitude of inbreeding depression in survival of Darwin's finches. Evolution 56: 1229-1239.

Keller LF, Waller DM (2002). Inbreeding effects in wild populations. Trends Ecol Evol 17: 230-241.
Koelewijn HP (1998). Effects of different levels of inbreeding on progeny fitness in Plantago coronopus. Evolution 52: 692-702.

Kristensen T, Dahlgaard J, Loeschcke V (2003). Effects of inbreeding and environmental stress on fitness - using Drosophila buzzatii as a model organism. Conserv Genet 4: $453-465$.

Lynch M (1988). Design and analysis of experiments on random drift and inbreeding depression. Genetics 120: 791-807.

Lynch M, Walsh B (1998). Genetics and Analysis of Quantitative Traits. Sinauer: Massachusetts.

Miller PS (1994). Is inbreeding depression more severe in a stressful environment? Zoo Biol 13: 195-208.

Mills LS, Smouse PE (1994). Demographic consequences of inbreeding in remnant populations. Am Nat 144: 412-431.

Morton NE, Crow JF, Muller HJ (1956). An estimate of the mutational damage in man from data on consanguineous marriages. Proc Nat Acad Sci USA 42: 855-863.

Norman JK, Sakai AK, Weller SG, Dawson TE (1995). Inbreeding depression in morphological and physiological traits of Schiedea lydgatei (Caryophyllaceae) in two environments. Evolution 49: 297-306.

Osenberg CW, Sarnelle O, Cooper SD, Holt RD (1999). Resolving ecological questions through meta-analysis: goals, metrics, and models. Ecology 80: 1105-1117.

Palmer AR (2000). Quasireplication and the contract of error: lessons from sex ratios, heritabilities, and fluctuating asymmetry. Ann Rev Ecol Syst 31: 441-480.

Pray LA, Schwartz JM, Goodnight CJ, Stevens L (1994). Environmental dependency of inbreeding depression: implications for conservation biology. Conserv Biol 8: 562-568.

Preziosi RF, Fairbairn DJ, Roff DA, Brennan JM (1996). Body size and fecundity in the waterstrider Aquarius remigis: a test of Darwin's fecundity advantage hypothesis. Oecologia 108: 424-431.

Ralls K, Ballou JD, Templeton A (1988). Estimates of lethal equivalents and the cost of inbreeding in Mammals. Conserv Biol 2: 185-192.

Reed DH, Briscoe D, Frankham R (2002). Inbreeding and extinction: the effect of environmental stress and lineage. Conserv Genet 3: 301-307.

Reed DH, Bryant EH (2000). Experimental tests of minimum viable population size. Anim Conserv 3: 7-14.

Reed DH, Bryant EH (2001). Fitness, genetic load, and purging in populations of the housefly. Conserv Genet 2: 57-62.

Reed DH, Lowe EH, Briscoe DA, Frankham R (2003). Fitness and adaptation in a novel environment: effect of inbreeding, prior environment, and lineage. Evolution 57: $1822-1828$

Reed DH, Frankham R (2003). Correlation between fitness and genetic diversity. Conserv Biol 17: 230-237.

Roff DA (1997). Evolutionary Quantitative Genetics. Chapman \& Hall: New York.

Schemske DW (1983). Breeding system and habitat effects on fitness components in three neotropical Costus (Zingiberaceae). Evolution 37: 523-539.

Schmitt JE, Ehrhardt DW (1990). Enhancement of inbreeding depression by dominance and suppression in Impatiens capensis. Evolution 44: 269-278.

Sinervo B (1990). The evolution of maternal investment in lizards: an experimental and comparative analysis of egg size and its effects on offspring performance. Evolution 44: 279-294.

Sinervo B, Doughty P, Huey RB, Zamudio K (1992). Allometric engineering: a casual analysis of natural selection on offspring size. Science 258: 1927-1930.

Templeton AR, Read B (1983). The elimination of inbreeding depression in a captive herd of Speke's gazelle. In: Schonewald CM, Chambers SM, MacBryde B, Thomas L (eds) Genetics and Conservation. Benjamin/Cummings: Menlo Park, pp 241-261. 
Thornhill NW (1993). The Natural History of Inbreeding and Outbreeding: Theoretical and Emprical Perspectives. University of Chicago Press: Chicago.

Uyenoyama MK, Holsinger KE, Waller DM (1993). Ecological and genetic factors directing the evolution of self-fertilization. Oxf Surv Evol Biol 9: 327-381.

Van Noordwijk AJ, Scharloo W (1981). Inbreeding in an island population of the great tit. Evolution 35: 674-688.

Vermeulen C, Bijlsma R (2004a). Changes in mortality patterns and temperature dependence of lifespan in Drosophila melanogaster caused by inbreeding. Heredity 92: 275-281.

Vermeulen CJ, Bijlsma R (2004b). Characterization of conditionally expressed mutants affecting age-specific survival in inbred lines of Drosophila melanogaster: lethal conditions and temperature-sensitive periods. Genetics 167: $1241-1248$.
Waller DM (1984). Differences in fitness between seedlings derived from cleistogamous and chasmogamous flowers in Impatiens capensis. Evolution 38: 427-440.

Whitlock MC, Ingvarsson PK, Hatfield T (2000). Local drift load and the heterosis of interconnected populations. Heredity 84: 452-457.

Wolfe LM (1993). Inbreeding depression in Hydrophyllum appendiculatum: role of maternal effects, crowding, and parental mating history. Evolution 47: 374-386.

\section{Appendix A1}

Summary of studies examined to calculate the expression of haploid lethal equivalents $(B)$ under benign and stressful conditions are referred in Table A1.

Table A1 Summary of studies examined to calculate the expression of haploid lethal equivalents $(B)$ under benign and stressful conditions

Reference
Armbruster et al (2000)
Bijlsma et al (1999)
Bijlsma et al (2000)
Carr and Eubanks (2002)
Carr et al (2003)
Chen (1993)
Cheptou et al (2000a)
Cheptou et al (2000b)
Cheptou et al (2001)

Dahlgaard and Hoffmann (2000)

Dahlgaard and Loeschcke (1997)

Dahlgaard et al (1995)

Dudash (1990)

Eckert and Barrett (1994)

Fowler and Whitlock (2002)

Haag et al (2002)

Haag et al (2003)

Hauser and Loeschcke (1996)

Henry et al (2003)

Ivey et al (2004)

Jiménez et al (1994)

Johnston (1992)

Joron and Brakefield (2003)

Koelewijn (1998)

Kristensen et al (2003)

\section{Miller (1994)}

Norman et al (1995)

Pray et al (1994)

Reed and Bryant (2001)

Reed et al (2002)
Drosophila melanogaster

Mimulus guttatus

Mimulus guttatus

Arianta arbustorum

Crepis sancta

Crepis sancta

Crepis sancta

Drosophila melanogaster Drosophila melanogastger Drosophila melanogaster

Sabatia angularis

Decodon verticillatus

Drosophila melanogaster

Daphnia magna

Daphnia magna

Lychnis flos-cuculi

Physa acuta

Mimulus guttatus

Peromyscus leucopus

Lobelia cardinalis

Bicyclus anynana

Plantago coronopus

Drosophila buzzati

Drosophila melanogaster

Schiedea lydgatei

Tribolium castaneum

Musca domestica

Drosophila melanogaster

\begin{tabular}{|c|c|c|c|}
\hline Stress ${ }^{\mathrm{a}}$ & Fitness measurement & $\mathrm{B}_{\text {benign }}$ & $\mathrm{B}_{\text {stress }}$ \\
\hline Field & Composite fitness & 3.62 & 3.91 \\
\hline Chem. & Composite fitness & 0.81 & 1.23 \\
\hline Chem. & Composite fitness & - & 0.86 \\
\hline Temp. & Composite fitness & - & 1.23 \\
\hline Biotic & Composite fitness & - & 0.94 \\
\hline Temp. & Extinction & 1.06 & 3.55 \\
\hline Chem. & Extinction & - & 2.58 \\
\hline Biotic & Number flowers & 0.40 & 0.86 \\
\hline Biotic & Number flowers & 0.43 & 0.85 \\
\hline Field & Survival & 0.18 & 0.07 \\
\hline Misc. & Survival & 0.08 & 0.02 \\
\hline Biotic & Composite fitness & 2.26 & 0.89 \\
\hline Biotic & Composite fitness & 0.08 & 0.63 \\
\hline Biotic & Composite fitness & 0.36 & 1.79 \\
\hline Temp. & Composite fitness & 1.11 & 1.99 \\
\hline Temp. & Egg-to-adult survival & 0.65 & 0.62 \\
\hline Temp. & Adult survivorship & 0.11 & 0.21 \\
\hline Field. & Composite fitness & 2.75 & 1.49 \\
\hline Biotic & Survival & 0.38 & 0.88 \\
\hline Biotic & Survival & 0.11 & 0.88 \\
\hline Temp. & Survival & 0.33 & 0.41 \\
\hline Biotic & Survival & - & 0.33 \\
\hline Misc & Survival & - & 0.44 \\
\hline Biotic & Composite fitness & 0.46 & 2.21 \\
\hline Biotic & Composite fitness & 2.37 & 2.43 \\
\hline Biotic & Composite fitness & - & 3.17 \\
\hline Misc. & Composite fitness & 2.21 & 4.58 \\
\hline Field & Survivorship & 0.06 & 0 \\
\hline Biotic & Composite fitness & 0.76 & 1.75 \\
\hline Field & Survival & 0.23 & 6.32 \\
\hline Field & Composite fitness & 0.42 & 0.42 \\
\hline Field & Composite fitness & 0.01 & 0.50 \\
\hline Field & Male mating success & 0.83 & 2.24 \\
\hline Field & Seed production & 0.16 & 1.92 \\
\hline Chem. & Composite fitness & 0.33 & 0.21 \\
\hline Temp. & Composite fitness & - & 1.59 \\
\hline Temp & Composite fitness & - & 0.72 \\
\hline Temp. & Composite fitness & 1.14 & 0.92 \\
\hline Temp. & Composite fitness & - & 1.04 \\
\hline Chem. & Composite fitness & - & 1.16 \\
\hline Misc. & Composite fitness & 2.01 & 1.88 \\
\hline Misc. & Composite fitness & 0.56 & 0.45 \\
\hline Misc. & Viability & 1.23 & 2.98 \\
\hline Temp. & Viability & - & 2.47 \\
\hline Chem. & Extinction & 1.15 & 1.68 \\
\hline Chem. & Extinction & - & 2.08 \\
\hline Chem. & Extinction & - & 2.13 \\
\hline
\end{tabular}


Table A1 Continued

\begin{tabular}{|c|c|c|c|c|c|}
\hline Reference & Organism & Stress $^{\mathrm{a}}$ & Fitness measurement & $\mathrm{B}_{\text {benign }}$ & $\mathrm{B}_{\text {stress }}$ \\
\hline \multirow[t]{3}{*}{ Schemske (1983) } & Costus laevis & Misc. & Composite fitness & 0.71 & 0.99 \\
\hline & Costus guanaiensis & Misc. & Composite fitness & 0.68 & 0.86 \\
\hline & Costus allenii & Misc. & Composite fitness & 1.35 & 1.64 \\
\hline Schmitt and Ehrhardt (1990) & Impatiens capensis & Biotic & Biomass & 0.15 & 0 \\
\hline Waller (1984) & Impatiens capensis & Biotic & Biomass & 0.73 & 0.65 \\
\hline Wolfe (1993) & Hydrophyllum appendicilatus & Biotic & Growth rate & 0.12 & 0.59 \\
\hline
\end{tabular}

${ }^{a}$ Biotic $=$ increased inter- or intra-specific density, exposure to parasites, herbivory, or light deprivation; Chem. = exposure to noxious or toxic chemical; Field = natural as opposed to lab or greenhouse conditions; Misc. = nutrient deprivation, desiccation, or a combination of Biotic, Chem., Field, and/or Temp.; Temp. = Temperature. 